\title{
Epidemiology of Renal Cell Carcinoma
}

\author{
Sandeep Anand Padala ${ }^{\mathrm{a}}$, Adam Barsouk ${ }^{\mathrm{b}}$, Krishna Chaitanya Thandrac ${ }^{\mathrm{c}}$, \\ Kalyan Saginalad ${ }^{\text {, Azeem Mohammed }}{ }^{\mathrm{a}}$, Anusha Vakitie, \\ Prashanth Rawla ${ }^{\mathrm{f}, \mathrm{h}}$, Alexander Barsouk ${ }^{\mathrm{g}}$
}

\begin{abstract}
Though renal cell carcinoma (RCC) accounts for $2 \%$ of global cancer diagnoses and deaths, it has more than doubled in incidence in the developed world over the past half-century, and today is the ninth most common neoplasm in the United States (US). While North America and Western Europe have the highest disease burden (with the Belarus highest in incidence), Latin America, Asia and Africa are projected to see an increase in incidence as nation's transition to a Western lifestyle. Most cases of RCC are discovered incidentally on imaging, and survival is highly dependent on the stage at diagnosis, with the metastatic disease having only a $12 \% 5$-year survival rate. Two-thirds of RCC diagnoses are made in men, and the average age of diagnosis in the US is 64 . Those with genetic predispositions, namely von Hippel-Lindau disease, tend to be diagnosed 20 years earlier. RCC has a greater incidence among Hispanics and Native Americans, and a lower survival rate among African Americans in the US. Modifiable risk factors for RCC include smoking, obesity, poorly-controlled hypertension, diet and alcohol, and occupational exposures. Prevention strategies aimed at improving survival and reducing disparities include addressing lifestyle factors and access to regular healthcare among underserved populations and in developing nations, as well as more rigorous imaging guidelines to detect $\mathrm{RCC}$ at an earlier stage. A stronger understanding of global RCC epidemiology can facilitate prevention efforts, especially in developing nations and underserved communities where disease burden is predicted to rise in the coming decades.
\end{abstract}

Keywords: Kidney cancer; Renal cell carcinoma; Epidemiology; In-

Manuscript submitted March 23, 2020, accepted May 4, 2020

aDepartment of Medicine, Nephrology, Augusta University, Medical College of Georgia, Augusta, GA 30912, USA

bHillman Cancer Center, University of Pittsburgh, Pittsburgh, PA 15232, USA 'Department of Pulmonary and Critical Care Medicine, Sentara Virginia Beach General Hospital, Virginia Beach, VA, USA

dPlains Regional Medical Group Internal Medicine, Clovis, NM 88101, USA eDepartment of Medicine, Hematology-Oncology, Augusta University, Medical College of Georgia, Augusta, GA 30912, USA

fDepartment of Medicine, Sovah Health, Martinsville, VA 24112, USA

gAllegheny Health Network, Pittsburgh, PA, USA

hCorresponding Author: Prashanth Rawla, Department of Internal Medicine, Sovah Health, 320 Hospital Dr, Martinsville, VA 24112, USA.

Email: rawlap@gmail.com

doi: https://doi.org/10.14740/wjon1279 cidence; Mortality; Trends; Survival; Etiology; Risk factors; Prevention

\section{Introduction}

Renal cell carcinoma (RCC) is an insidious neoplasm, accounting for approximately $2 \%$ of global cancer diagnoses and deaths, and projected to increase in burden worldwide [1]. Cancers of the kidney and renal pelvis have rapidly become more common in the developed world over the past decades, more than doubling in incidence in the United States (US) since 1975 [2].

Most RCCs occur in the cortex of the kidney, which is composed of the glomerulus, tubular apparatus and collecting duct. Cancers of the renal pelvises resemble urothelial (bladder) cancer in histology and behavior [3].

Most RCC cases in the developed world are found incidentally on imaging, typically with a magnetic resonance imaging (MRI), computed tomography (CT) scan, or ultrasound. Only $10 \%$ of patients present with the "classic triad" of symptoms: hematuria, flank pain and palpable masses. Other common symptoms include fever, weight loss and leukocytosis. Approximately $20 \%$ of patients also suffer from a variety of paraneoplastic syndromes, including hypercalcemia due to parathyroid-related hormone peptide, polycythemia due to erythropoietin, Cushing's syndrome due to adrenocorticotropic hormone (ACTH) and hypertension due to renin over-production. Rarely, RCC is suspected following the diagnosis of a left-sided varicocele due to tumor involvement and obstruction of the left renal vein [4].

Depending on patient characteristics and extent of the disease, the neoplasm is either surgically resected and ablated or percutaneously biopsied and immunohistochemically (IHC) stained to determine systemic therapy. The IHC stain for the immunosuppressive marker programmed death ligand-1 (PDL1) has become especially predictive as PD-1 inhibitors like pembrolizumab and nivolumab have become the firstline standard of care in PDL1-positive metastatic disease [5]. PDL1-positive disease accounts for approximately $8.2 \%$ of cases and is associated with more advanced disease and lower survival [6]. Even PDL1-negative disease is highly resistant to chemotherapy and radiation therapy, other immunotherapies such as aldesleukin (IL-2) and targeted therapies (such as su- 


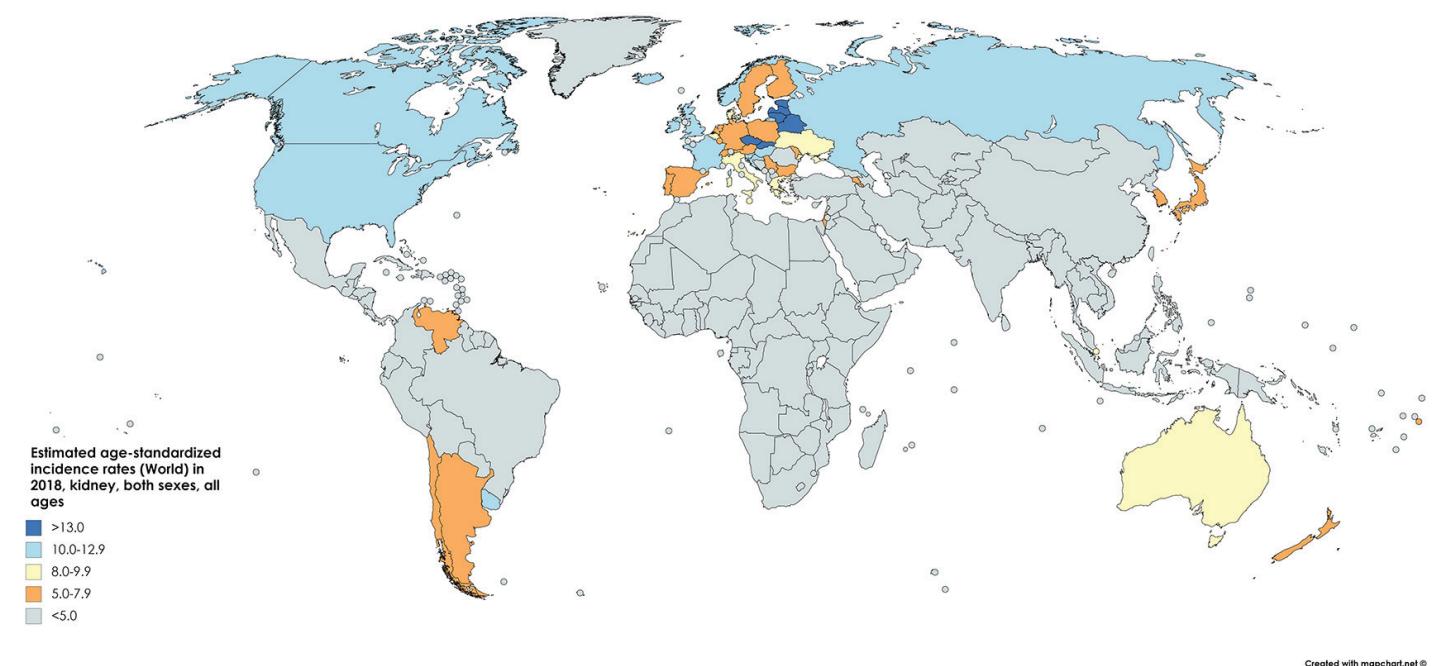

Figure 1. Map showing estimated age-standardized incidence rates for kidney cancer worldwide in 2018 , in males including all ages. Created with mapchart.net. Data obtained from GLOBOCAN 2018 [7].

nitinib, a vascular endothelial growth factor (VEGF) tyrosine kinase inhibitor) are typically employed in the treatment of the metastatic disease.

As more nations adopt the Western lifestyle, the global burden of RCC is projected to continue to rapidly increase. Incidental findings remain the primary form of RCC diagnosis, and despite new treatment options, late-stage diagnoses have abysmally low survival rates. A better understanding of RCC epidemiology and risk factors may help curb growing disease burden through prevention as well as facilitate earlier diagnosis and more targeted treatment options, thereby improving survival for a disease that claims 175,000 lives each year.

\section{Epidemiology}

\section{Incidence}

According to 2018 GLOBOCAN data, an estimated 403,000 people a year are diagnosed with neoplasms of the kidney, constituting $2.2 \%$ of all cancer diagnoses [7]. Of these, approximately 254,500 cases are diagnosed in males and 148,800 in females, reflecting a relative risk (RR) of about 1.7 for men compared to women. The cumulative global risk of developing the disease is $0.69 \%$ among men and $0.35 \%$ among women, which results in an age-standardized rate (ASR) of 6.0 and 3.1 among men and women, respectively (with a global average of 4.4). North America has the greatest incidence (ASR = 10.9/100,000) with Western Europe (9.7) and Australia/New Zealand (9.6) not far behind (Fig. 1 [7]). Belarus is the nation with the highest incidence in the world $(16.8 / 100,000)$, while many central African nations have an effective incidence near or equal to 0 [1].

RCC is the seventh most common form of neoplasm in the developed world. The surveillance, epidemiology, and end re- sults (SEER) statistics report that in the US, about 74,000 new cases of kidney cancer were diagnosed in 2019, accounting for $4.2 \%$ of all cancer diagnoses (almost double the global average). The incidence was first reported in 1975 as 7.1/100,000. In 2016, this resulted in an incidence rate of 14.9/100,000. This steady rise has made kidney cancer one of the fastestgrowing cancer diagnoses in the US. However, since peaking at 16.0/100,000 in 2008, kidney cancer incidence has plateaued [2].

\section{Mortality}

The GLOBOCAN statistics report mortality of 175,000 people from kidney cancer in 2018. This figure constitutes $1.8 \%$ of global cancer deaths. With approximately 114,000 men and 61,000 women perishing from the disease in 2018, the RR of mortality for men is 1.87 , even greater than the relative incidence risk (1.71) (Fig. 2 [7]). The cumulative risk of death is $0.28 \%$ among men worldwide and $0.12 \%$ among women, with ASRs of 2.6 and 1.1, respectively [1] (Fig. 3 [7]).

In the US, SEER program estimates that for the year 2020 the number of new cases of kidney cancer is 73,750 and deaths is 14,830 , accounting for $2.4 \%$ of all cancer-related deaths. Despite a doubling incidence, the age-standardized mortality in 2016 was the same as in 1975 when the statistic was first reported, 3.6/100,000. Mortality peaked at 4.3/100,000 in the years 1992 - 1994, and has since gradually declined to current levels, likely due to improving diagnostic modalities and treatments [2].

\section{Survival}

With a 76\% 5-year relative survival rate in the US (2009 2015), RCC is the deadliest urological cancer. This survival 


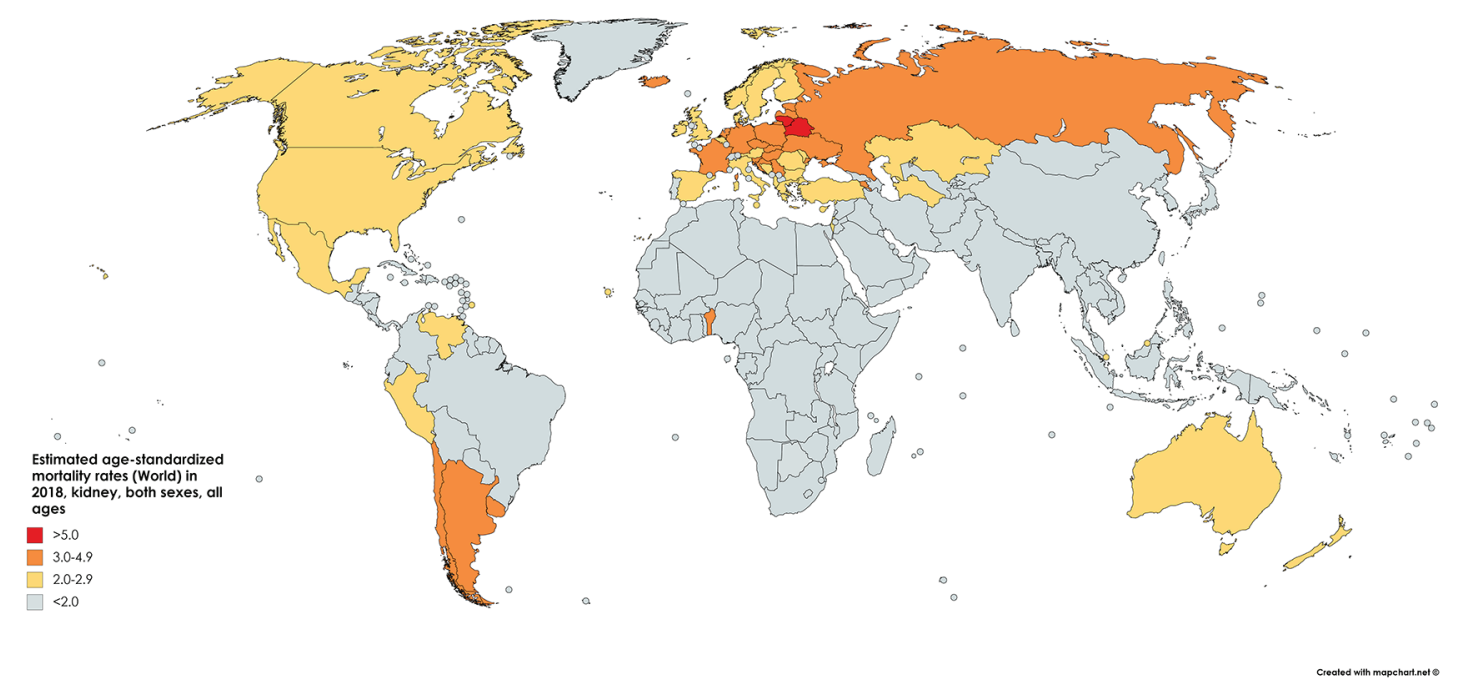

Figure 2. Map showing estimated age-standardized mortality rates for kidney cancer worldwide in 2018 , in males including all ages. Created with mapchart.net. Data obtained from GLOBOCAN 2018 [7].

rate has markedly improved since a low of $46.8 \%$ in 1977. Survival is highly dependent on the stage at diagnosis, with a 5 -year relative survival of $93 \%$ for stage I, localized disease, $72.5 \%$ for stage II/III regional disease (local lymph node involvement) and only $12 \%$ for stage IV metastatic disease [2, 8] (Fig. 4). About one-third of cases are diagnosed as metastatic, and a further $20-50 \%$ will progress to metastatic cancer despite surgical resection [9]. A large retrospective study of seven Latin American countries and Spain found the 5-year survival for resected RCC to be $86.1 \%$. Age, nodal metastases, performance status (Karnofsky score $<80$ ), fat invasion, tumor necrosis and tumor size $(>7 \mathrm{~cm})$ were all significantly associ- ated with worsened survival (in order of descending significance) [10]. Mangone et al have studied the trends in net survival from kidney cancer among six European Latin countries (SUDCAN population-based study) and found that, though there were some differences in survival, there were significant improvements in most countries [11].

Among those enrolled in clinical trials, a univariable analysis found those in the US/Canada with metastatic RCC had significantly higher survival than those in Western Europe (20.3 vs. 17.4 months), a difference which was not found in the multivariant analysis. Clinical trial participant survival was more variable in Latin America, Asia and Eastern Europe [12].

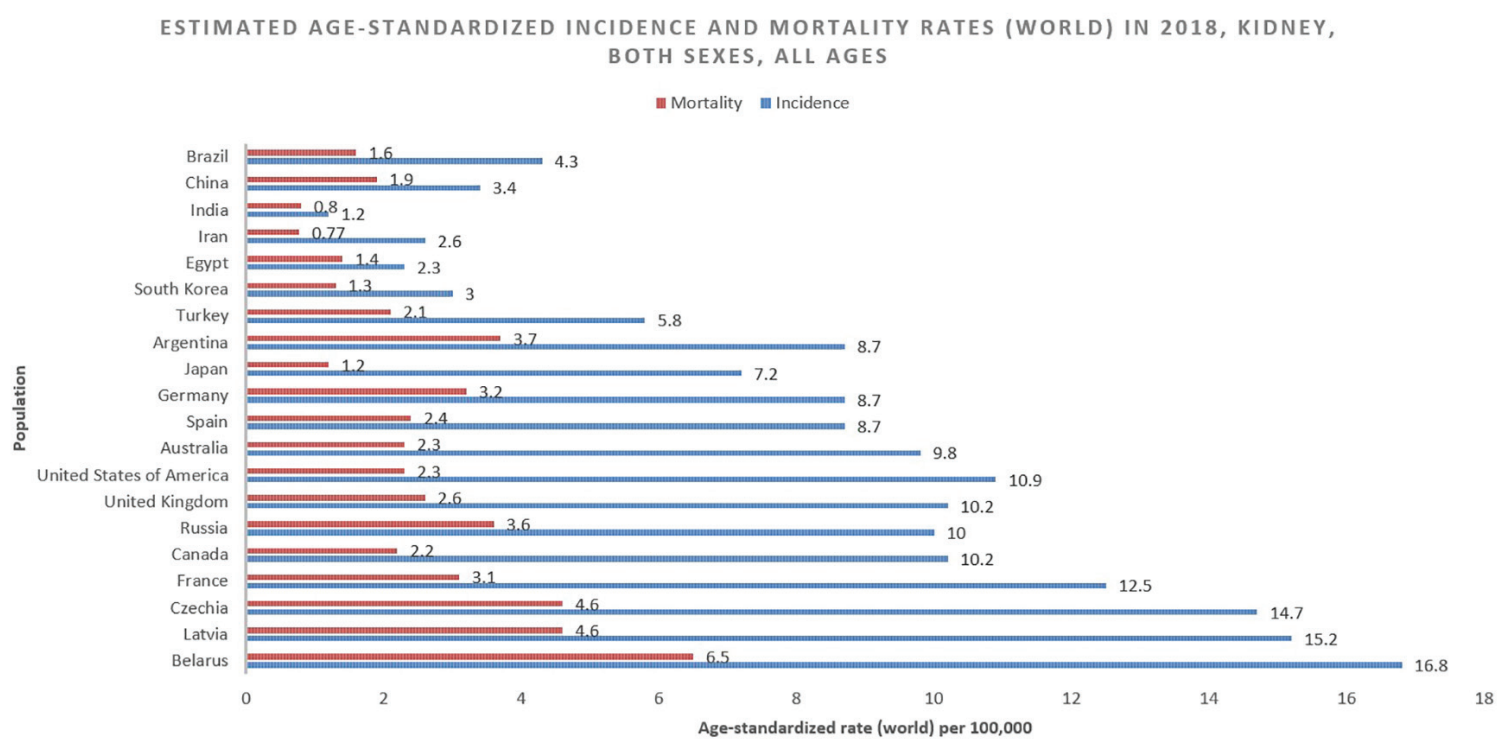

Figure 3. Bar chart showing estimated age-standardized incidence and mortality rates (World) in 2018, kidney, both sexes, all ages. Data obtained from GLOBOCAN 2018 [7]. 


\section{KIDNEY CANCER}

\section{5-YEAR SEER RELATIVE SURVIVAL RATES, 2009-2015 BY STAGE AT DIAGNOSIS AND SEX}

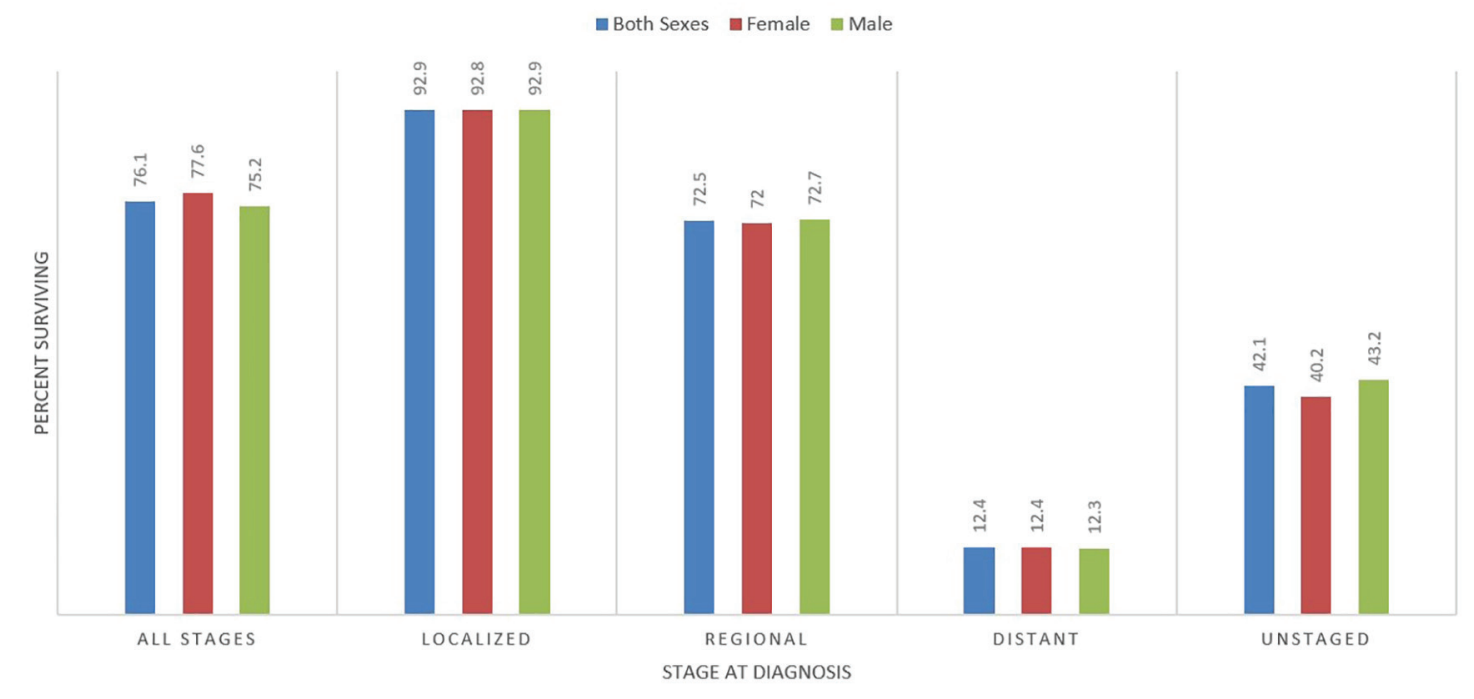

Figure 4. Kidney cancer 5-year SEER relative survival rates, 2009 - 2015 by stage at diagnosis and sex. Data source: US Mortality Files, National Center for Health Statistics, CDC [8].

\section{Etiology and Histology}

Ninety percent of RCCs are of the clear cell, papillary and chromophobe histological subtypes, with the clear cell being the most common and aggressive. These subtypes have significant prognostic and treatment-predictive value [13]. Clear cell RCC, which accounts for $75 \%$ of diagnoses, is a tumor of renal stem cells commonly in the proximal nephron and tubular epithelium and is most likely to hematogenously metastasize to the lungs, liver and bones [14]. Inactivating somatic mutations or deletions in the von Hippel-Lindau (VHL) tumor-suppressor gene region (chromosome arm $3 \mathrm{p}$ ) are implicated in as many as $45 \%$ of clear cell carcinoma cases. Those inheriting germline variants of this gene (VHL disease) and the tuberous sclerosis genes account for $5 \%$ of clear cell cases and are at an increased risk of younger-age, bilateral RCC [15]. While papillary RCC, which accounts for $10 \%$ of cases, has better survival than the clear cell, the prognosis is highly variable based on post-operative histological staining. Type 1 (basophilic) papillary carcinoma is typically higher-grade and more often associated with ganglial metastases and venous invasion than type 2 (eosinophilic) tumors. Papillary RCC largely resembles renal cortical adenoma in architecture and genetic abnormalities (trisomy 7 and 17 and loss of the Y chromosome); however, renal cortical adenomas tend to be smaller $(<1.5 \mathrm{~cm})$. Chromophobe RCC represents $5 \%$ of cases and carries the best prognosis, as metastases occur in only $7 \%$ of cases. Chromophobe RCC appears grossly, histologically and genetically similar to oncocytomas, with both being well-circumscribed, involving deletions of chromosomes $\mathrm{Y}$ and 1, arising from collecting duct intercalated cells (involved in acid-base regulation), and as- sociated with Birt-Hogg-Dube syndrome. Chromophobe RCC can be distinguished from oncocytomas with the absence of a central scar and a characteristic perinuclear halo. Medullary $\mathrm{RCC}$ is a rare form of RCC typically found in patients with sickle cell trait/disease or beta-thalassemia [16].

\section{Risk Factors}

\section{Unmodifiable}

Age

Sporadic RCC is a disease of older adults. The average of diagnosis in the US is 64 , though most patients are diagnosed between ages 65 and 74 (cumulatively) [2]. Those with VHL disease develop RCC at an average age of 44 and are much more likely to be diagnosed with bilateral disease [17]. The largest increase in incidence in the US over the past decades has been among those 75 and older [2]. Papillary RCC diagnoses were also significantly more likely to be made among those $>60$ than clear cell RCC, while chromophobe RCC diagnosis does not seem to be significantly associated with age, hinting at different mechanisms and timelines of pathogenesis among the histological subtypes [18].

Sex

Like most neoplasms, RCC is more common in men, with men 


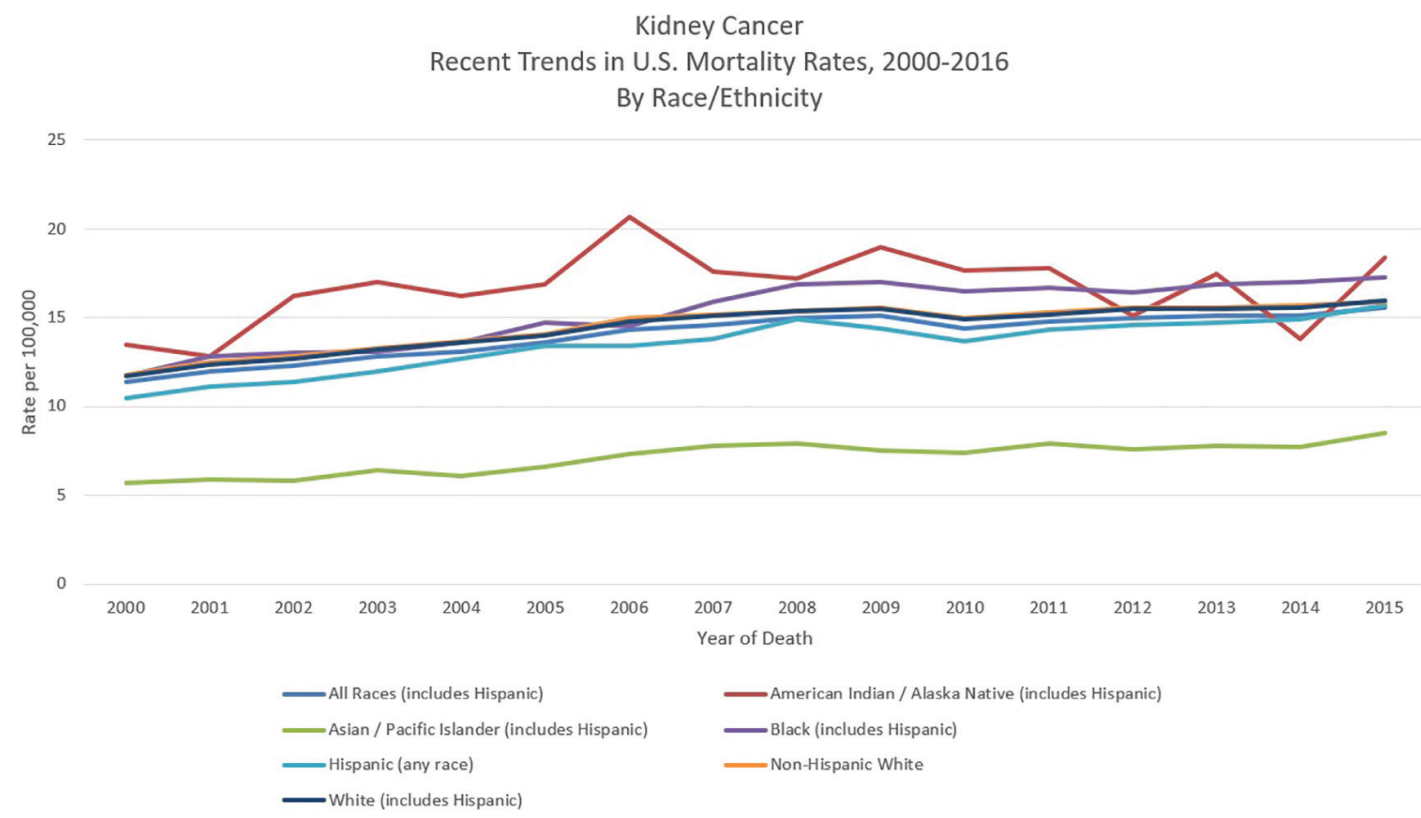

Figure 5. Kidney cancer recent trends in United States mortality rates, 2000 - 2016 by race/ethnicity. Data source: US Mortality Files, National Center for Health Statistics, CDC [8].

accounting for about two-thirds of global cases and deaths [1]. Part of this increased risk may be explained by greater rates of modifiable risk factors such as smoking, hypertension and obesity among men. Men also have lower survival rate [2]. By histological subtype, papillary RCC patients were the least likely to be women, while chromophobe RCC patients were far more commonly women than clear cell or papillary (but still not quite at a 1:1 ratio) [18]. The exact mechanism is not clear, but there is an increased risk of RCC with parity among women and also a possible correlation with hormonal factors [19-21].

\section{Race}

In the US, African Americans, Hispanic Americans and Native Americans have a greater risk of RCC than White Americans. One retrospective study found that Hispanic Americans had an almost three-fold increased odds of early RCC diagnosis, while Native Americans had an over six-fold increased odds, an effect that was especially pronounced for clear cell RCC. Interestingly, among Hispanics, speaking Spanish as one's primary language was associating with an increased risk of advanced RCC diagnosis [22]. While African Americans are typically diagnosed at an earlier stage of RCC than whites [23], their survival rates tend to be worse $[24,25]$ (Fig. 5 [8]). One study found that among comparable T1 RCC patients, African Americans were more likely to have positive surgical margins following robotic nephrectomy [26]. Interestingly, the clear cell subtype of RCC is more common among Caucasian Americans (partially due to increased risk of VHL disease) while the papillary subtype is more common among those of African or Caribbean descent [27]. Suggested factors underlying the racial disparity in RCC diagnosis and survival among minorities include education and socioeconomic status, diet and physical inactivity, poor living conditions, access to healthcare and loss to follow-up [25].

\section{Modifiable}

\section{Smoking}

Tobacco smoking is one of few modifiable risk factors for RCC (and largely the most significant), similar to lung cancer and bladder cancer. Cigarette smoke contains many carcinogens such as polycyclic aromatic hydrocarbons and beta-naphthylamine, as well as the highly addictive neurotransmitter-modulating substance nicotine. As they are filtered through the nephron, these particles are metabolized and promote inflammation and induce DNA damage, paving the way for carcinogenesis. One large retrospective analysis found current and former smokers had a 1.5- and 1.6-fold RR of RCC, respectively [28]. Increasing pack-years has been associated with increased risk (up to 2.03 for those with $20+$ pack-years), and RR was significantly reduced among those who had quit over 10 years ago [29]. Continued cigarette smoking after RCC diagnosis has also been associated with significantly worsened overall survival (OS) and progression-free survival (PFS) in advanced disease [30].

\section{Obesity}

Meta-analyses have found a consistent association between increased body mass index (BMI) and risk of RCC, much like with breast cancer, colorectal cancer and many other neo- 
plasms. While the precise pathogenesis remains unelucidated, obesity promotes resistance to insulin and insulin-like growth factor (facilitating uncontrolled tumor growth) [31], releases inflammatory cytokines, and disrupts metabolic homeostasis (such as stimulating the release of adiponectin) [32], leading to the over-production of DNA damaging free radicals. A study of the European Prospective Investigation into Cancer and Nutrition (EPIC) found that high BMI was associated with a 2.25 RR of RCC [33]. Another study found that obesity was particularly associated with an increased risk of the clear cell (RR $=1.8)$ and chromophobe $(\mathrm{RR}=2.2)$ subtypes of $\mathrm{RCC}$, while papillary RCC did not seem to show an association $(R R=1.2)$ [34]. One study found that adding roughly $5 \mathrm{~kg}$ in body weight could increase RCC risk by $25 \%$ in men and $35 \%$ in women [35]. According to a meta-analysis, regular physical activity was shown to reduce RCC risk by $22 \%$ [36].

\section{Diet and alcohol}

Diets rich in cruciferous have been associated in some studies with a lower risk of RCC [37], while those heavy in meat-based protein and fat and dairy are associated with higher risk [38]. However, these associations were disputed by the EPIC study in Europe, which did not find any significant association between diet and RCC risk [39]. The correlation between diet and RCC seems to be not as strong as in other neoplasms like gastric and colorectal cancer. While moderate drinking seems to show a slight protective effect against RCC, heavy drinking is associated with increased risk among both men and women [40, 41].

\section{Hypertension}

Hypertension damages the renal glomerulus and tubular apparatus and has been associated with an increased risk of kidney cancer. A case-control study in the US found that hypertension doubled overall risk (OR) for RCC. White Americans with hypertension had an ORR of 1.9 , while the OR was 2.8 for African Americans (possibly due to an increased prevalence of obesity). Time since hypertension diagnosis and poorly controlled hypertension both significantly further increased the risk of developing RCC. Both hypertension and obesity have been implicated in the racial disparity of RCC incidence and mortality in the US [42]. The aforementioned EPIC study found that among Europeans, high systolic $(>160 \mathrm{~mm} \mathrm{Hg})$ and diastolic $(>100 \mathrm{~mm} \mathrm{Hg})$ blood pressures were associated with a 2.48 and 2.34 RR of RCC, respectively [43]. The use of statins to control blood pressure among those with RCC could significantly improve survival; however, statin use was not shown to prevent RCC diagnosis [44].

\section{Occupational exposure and drugs}

While RCC is not classified as an occupational neoplasm (like bladder cancer or mesothelioma), several occupational exposures have been noted. Most prevalently, trichloroethylene, a solvent used in degreasing agents, spray fixatives for art, and public drinking water has been associated with RCC, liver cancer and lymphoma [45]. Specifically, the chemical seems to be activated by the pathway involved in glutathione transfer in the liver and kidney, causing DNA adducts, renal cell genotoxicity and cytotoxicity [46]. An estimated $10 \%$ of the US population has detectable levels of the toxic agent in their blood [45]. Other occupational chemicals associated with RCC include asbestos, benzene, vinyl chloride, herbicides and cadmium, as well as an overdose of the popular painkiller acetaminophen (US trade name Tylenol). Regular use of non-aspirin non-steroidal anti-inflammatory drugs has also been associated with an increased risk of RCC, likely because these agents inhibit prostaglandins which are necessary for proper kidney function [47].

\section{Prevention and Screening}

Smoking cessation, a healthy diet and regular exercise are the most evidence-backed means of prevention for RCC. The Mediterranean diet and United States Department of Agriculture (USDA) designed Dietary Approaches to Stop Hypertension (DASH) diet, both of which consist of high levels of fruits, vegetables and plant products and low levels of red meat and fatty dairy, have been shown to decrease the risk of many cancers and have favorable effects on body weight, hypertension, glucose and lipids, all of which are implicated in RCC tumorigenesis [48]. Better control of hypertension through lifestyle modification, statins and other interventions is associated with a lower risk of RCC [41, 42]. Early interventions could be of particular benefit to minority populations in the US like African Americans and Hispanics, whose higher rates of early-age hypertension may predispose them to worse RCC outcomes [42]. Regular exercise helps to maintain healthy blood pressure and weight, but may also further reduce the risk of cancer independent of the aforementioned factors [49]. Smoking cessation gradually decreases the risk of RCC, with an over a twofold reduction in risk after 10 years of cessation [30].

Greater awareness of RCC risk factors and access to healthcare, especially among underserved populations in the developed world and developing nations, may help reduce disparities and improve outcomes. Populations at heightened risk of RCC due to genetic predispositions, high blood pressure, obesity or smoking and drinking status should be followed regularly and offered imaging (with ultrasound, MRI, or CT scan) when suspected as the prognosis is far more favorable when diagnosed early [25]. There are no randomized controlled trials (RCTs) to advocate for screening imaging studies in suspected RCC patients. Public health campaigns against smoking and obesity have likewise played a role in curbing the growing incidence of RCC in the developed world and could serve as examples for developing nations faced with an increasing disease burden.

\section{Conclusion}

While RCC accounts for $2 \%$ of global cancer diagnoses and 
deaths, it has rapidly grown in incidence in the developed world, becoming the ninth most common cancer diagnosis in the US. RCC is the deadliest urological neoplasm and has a dismal late-stage, 5-year survival rate of $12 \%$. Clear cell is the most common histological subtype, followed by papillary and chromophobe, and shows the strongest associations with many modifiable and unmodifiable risk factors. RCC is more common in older men and minorities in the US, where significant racial disparities persist in RCC survival. Modifiable risk factors such as smoking, obesity, uncontrolled hypertension, poor diet and occupational exposure are prime candidates for prevention efforts in the campaign against this aggressive cancer.

\section{Acknowledgments}

None to declare.

\section{Financial Disclosure}

No funding to disclose.

\section{Conflict of Interest}

Alexander Barsouk served as a consultant for Bristol-Myers Squibb. The other authors declare no conflict of interest.

\section{Author Contributions}

Conception and design: SAP, ADB, KCT, KS, AM. Analysis and interpretation, drafting and critical revision of the article: SAP, ADB, KCT, KS, AM, AV, PR, ALB. Final approval of the article: SAP, ADB, KCT, KS, AM, AV, PR, ALB.

\section{Data Availability}

The authors declare that data supporting the findings of this study are available within the article.

\section{References}

1. Bray F, Ferlay J, Soerjomataram I, Siegel RL, Torre LA, Jemal A. Global cancer statistics 2018: GLOBOCAN estimates of incidence and mortality worldwide for 36 cancers in 185 countries. CA Cancer J Clin. 2018;68(6):394424.

2. Howlander N, Noone AM, Krapcho M, et al. SEER cancer statistics review 1975-2016. Natl. Cancer Institute. 2019.

3. Lote CJ. Principles of renal physiology. Springer, New York, NY. 2013.

4. Decastro GJ, McKiernan JM. Epidemiology, clinical staging, and presentation of renal cell carcinoma. Urol Clin North Am. 2008;35(4):581-592; vi.

5. De Maeseneer DJ, Delafontaine B, Rottey S. Checkpoint inhibition: new treatment options in urologic cancer. Acta Clin Belg. 2017;72(1):24-28.

6. Chipollini J, da Costa WH, Werneck da Cunha I, de Almeida EPF, Guilherme OSP, Azizi M, Spiess PE, et al. Prognostic value of PD-L1 expression for surgically treated localized renal cell carcinoma: implications for risk stratification and adjuvant therapies. Ther Adv Urol. 2019;11:1756287219882600.

7. Global cancer observatory: cancer today. Lyon, France: International Agency for Research on Cancer. https://gco. iarc.fr/today. Accessed March 2, 2020.

8. SEER Explorer. https://seer.cancer.gov/explorer/index. html. Accessed March 2, 2020.

9. Campbell SC, Lane BR. Malignant renal tumors. Campbell-Walsh Urol. 2012.

10. Zequi S de C, Mourao TC, de Oliveira MM, Curado MP, Gueglio G, de Costa WH, Zuniga A, et al. Predictors of survival outcomes in non-metastatic renal cell carcinoma in Latin America and Spain: a multicentric analysis. Kidney Cancer. 2019;3(4):253-261.

11. Mangone L, Bossard N, Marcos-Gragera R, Pezzarossi A, Roncaglia F, Rossie PG, the GRELL EUROCARE-5 Working Group. Trends in net survival from kidney cancer in six European Latin countries: results from the SUDCAN population-based study. European Journal of Cancer Prevention. 2017;26:S121-S127.

12. Fay AP, McKay RR, Lin X, Simantov R, Choueiri TK. Impact of geographic regions on overall survival in patients with metastatic renal cell carcinoma: results from an international clinical trials database. J Glob Oncol. 2018;4:1-14.

13. Muglia VF, Prando A. Renal cell carcinoma: histological classification and correlation with imaging findings. Radiol Bras. 2015;48(3):166-174.

14. Chevrier S, Levine JH, Zanotelli VRT, Silina K, Schulz D, Bacac M, Ries CH, et al. An Immune Atlas of Clear Cell Renal Cell Carcinoma. Cell. 2017;169(4):736-749 e718.

15. Creighton CJ, Hernandez-Herrera A, Jacobsen A, Levine DA, Mankoo P, Schultz N, Du Y, et al. Integrated analyses of microRNAs demonstrate their widespread influence on gene expression in high-grade serous ovarian carcinoma. PLoS One. 2012;7(3):e34546.

16. Prasad SR, Humphrey PA, Catena JR, Narra VR, Srigley JR, Cortez AD, Dalrymple NC, et al. Common and uncommon histologic subtypes of renal cell carcinoma: imaging spectrum with pathologic correlation. Radiographics. 2006;26(6):1795-1806; discussion 1806-1710.

17. Maher ER, Neumann HP, Richard S. von Hippel-Lindau disease: a clinical and scientific review. Eur J Hum Genet. $2011 ; 19(6): 617-623$.

18. Lipworth L, Morgans AK, Edwards TL, Barocas DA, Chang SS, Herrell SD, Penson DF, et al. Renal cell cancer histological subtype distribution differs by race and sex. BJU Int. 2016;117(2):260-265.

19. Kabat GC, Silvera SA, Miller AB, Rohan TE. A cohort 
study of reproductive and hormonal factors and renal cell cancer risk in women. Br J Cancer. 2007;96(5):845-849.

20. Abdul KS, Jayasinghe SS, Chandana EP, Jayasumana C, De Silva PM. Arsenic and human health effects: A review. Environ Toxicol Pharmacol. 2015;40(3):828-846.

21. Dell'Atti L, Borghi C, Galosi AB. Laparoscopic Approach in Management of Renal Cell Carcinoma During Pregnancy: State of the Art. Clin Genitourin Cancer. 2019;17(4):e822-e830.

22. Batai K, Harb-De la Rosa A, Lwin A, Chaus F, Gachupin FC, Price E, Lee BR. Racial and ethnic disparities in renal cell carcinoma: an analysis of clinical characteristics. Clin Genitourin Cancer. 2019;17(1):e195-e202.

23. Mafolasire A, Yao X, Nawaf C, Suarez-Sarmiento A, Chow WH, Zhao W, Corley D, et al. Racial disparities in renal cell carcinoma: a single-payer healthcare experience. Cancer Med. 2016;5(8):2101-2108.

24. Chow WH, Shuch B, Linehan WM, Devesa SS. Racial disparity in renal cell carcinoma patient survival according to demographic and clinical characteristics. Cancer. 2013;119(2):388-394.

25. Sims JN, Yedjou CG, Abugri D, Payton M, Turner T, Miele L, Tchounwou PB. Racial disparities and preventive measures to renal cell carcinoma. Int J Environ Res Public Health. 2018;15(6):1089.

26. Chen VS, Abouassaly R, Gonzalez CM, Kutikov A, Smaldone MC, Meropol NJ, Psutka SP, et al. Association of race and margin status among patients undergoing robotic partial nephrectomy for $\mathrm{T} 1$ renal cell carcinoma: Results from a population-based cohort. Urol Oncol. 2017;35(11):662 e617-662 e621.

27. Olshan AF, Kuo TM, Meyer AM, Nielsen ME, Purdue MP, Rathmell WK. Racial difference in histologic subtype of renal cell carcinoma. Cancer Med. 2013;2(5):744749.

28. Tsivian M, Moreira DM, Caso JR, Mouraviev V, Polascik TJ. Cigarette smoking is associated with advanced renal cell carcinoma. J Clin Oncol. 2011;29(15):2027-2031.

29. Hunt JD, van der Hel OL, McMillan GP, Boffetta P, Brennan P. Renal cell carcinoma in relation to cigarette smoking: meta-analysis of 24 studies. Int $\mathrm{J}$ Cancer. 2005;114(1):101-108.

30. Keizman D, Gottfried M, Ish-Shalom M, Maimon N, Peer A, Neumann A, Hammers H, et al. Active smoking may negatively affect response rate, progression-free survival, and overall survival of patients with metastatic renal cell carcinoma treated with sunitinib. Oncologist. 2014;19(1):51-60.

31. Pollak M. The insulin and insulin-like growth factor receptor family in neoplasia: an update. Nat Rev Cancer. 2012;12(3):159-169.

32. Liao LM, Schwartz K, Pollak M, Graubard BI, Li Z, Ruterbusch J, Rothman N, et al. Serum leptin and adiponectin levels and risk of renal cell carcinoma. Obesity (Silver Spring). 2013;21(7):1478-1485.

33. Pischon T, Lahmann PH, Boeing H, Tjonneland A, Halkjaer J, Overvad K, Klipstein-Grobusch K, et al. Body size and risk of renal cell carcinoma in the European Prospective Investigation into Cancer and Nutrition (EPIC).
Int J Cancer. 2006;118(3):728-738.

34. Callahan CL, Hofmann JN, Corley DA, Zhao WK, Shuch B, Chow WH, Purdue MP. Obesity and renal cell carcinoma risk by histologic subtype: A nested case-control study and meta-analysis. Cancer Epidemiol. 2018;56:3137.

35. Macleod LC, Hotaling JM, Wright JL, Davenport MT, Gore JL, Harper J, White E. Risk factors for renal cell carcinoma in the VITAL study. J Urol. 2013;190(5):16571661.

36. Keimling M, Behrens G, Schmid D, Jochem C, Leitzmann MF. The association between physical activity and bladder cancer: systematic review and meta-analysis. Br J Cancer. 2014;110(7):1862-1870.

37. Liu B, Mao Q, Wang X, Zhou F, Luo J, Wang C, Lin $\mathrm{Y}$, et al. Cruciferous vegetables consumption and risk of renal cell carcinoma: a meta-analysis. Nutr Cancer. 2013;65(5):668-676.

38. Daniel CR, Schwartz KL, Colt JS, Dong LM, Ruterbusch JJ, Purdue MP, Cross AJ, et al. Meat-cooking mutagens and risk of renal cell carcinoma. Br J Cancer. 2011;105(7):1096-1104.

39. Weikert S, Boeing H, Pischon T, Olsen A, Tjonneland A, Overvad K, Becker N, et al. Fruits and vegetables and renal cell carcinoma: findings from the European prospective investigation into cancer and nutrition (EPIC). Int J Cancer. 2006;118(12):3133-3139.

40. Wozniak MB, Brennan P, Brenner DR, Overvad K, Olsen A, Tjonneland A, Boutron-Ruault MC, et al. Alcohol consumption and the risk of renal cancers in the European prospective investigation into cancer and nutrition (EPIC). Int J Cancer. 2015;137(8):1953-1966.

41. Lew JQ, Chow WH, Hollenbeck AR, Schatzkin A, Park Y. Alcohol consumption and risk of renal cell cancer: the NIH-AARP diet and health study. Br J Cancer. 2011;104(3):537-541.

42. Colt JS, Schwartz K, Graubard BI, Davis F, Ruterbusch J, DiGaetano R, Purdue M, et al. Hypertension and risk of renal cell carcinoma among white and black Americans. Epidemiology. 2011;22(6):797-804.

43. Weikert S, Boeing H, Pischon T, Weikert C, Olsen A, Tjonneland A, Overvad K, et al. Blood pressure and risk of renal cell carcinoma in the European prospective investigation into cancer and nutrition. Am J Epidemiol. 2008;167(4):438-446.

44. Zhang XL, Liu M, Qian J, Zheng JH, Zhang XP, Guo CC, Geng J, et al. Statin use and risk of kidney cancer: a metaanalysis of observational studies and randomized trials. Br J Clin Pharmacol. 2014;77(3):458-465.

45. Moore LE, Boffetta P, Karami S, Brennan P, Stewart PS, Hung R, Zaridze D, et al. Occupational trichloroethylene exposure and renal carcinoma risk: evidence of genetic susceptibility by reductive metabolism gene variants. Cancer Res. 2010;70(16):6527-6536.

46. Lock EA, Reed CJ. Trichloroethylene: mechanisms of renal toxicity and renal cancer and relevance to risk assessment. Toxicol Sci. 2006;91(2):313-331.

47. Choueiri TK, Je Y, Cho E. Analgesic use and the risk of kidney cancer: a meta-analysis of epidemiologic studies. 
Int J Cancer. 2014;134(2):384-396.

48. Ostan R, Lanzarini C, Pini E, Scurti M, Vianello D, Bertarelli C, Fabbri C, et al. Inflammaging and cancer: a challenge for the Mediterranean diet. Nutrients.
2015;7(4):2589-2621.

49. Behrens G, Leitzmann MF. The association between physical activity and renal cancer: systematic review and meta-analysis. Br J Cancer. 2013;108(4):798-811. 